\title{
Basalt Nuclear-Waste Repository Remote Sensing Using Electromagnetic Techniques
}

\author{
W. D. Daily
}

H. M. Buettner

Manuscript date: January 1984

\author{
DISCLAIMER
}

This report was prepared as an account or work sponsored by an agency of the United States Government. Neither the United States Government nor any agency thereof, nor any of their employees, makes any warranty, express or implied, or assumes any legal liability or responsibility for thr, aceuracy. comp'eteness, or usefulness of any information, apparatus, product, or process disclosed, or represents that its use would not infringe privately owned rights. Reference berein to any specific commercial ptodtet, process, or service by trade name, trademark, manufacturer, or utherwise does not necessarily constitute or imply its endorsement, recommendation, or favoring by the United States Government or any agency thereof. The views and opinions of authors expressed herein do not necessarily state or reflect those of the United States Government of any agency thereof.

\section{LAWRENCE LIVERMORE INATIONAL LABORATORY University of California - Livermore, California - 94550}




\section{Contenis}

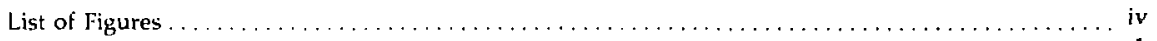

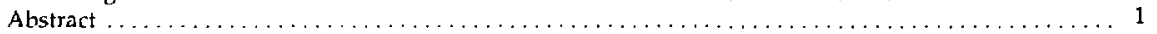

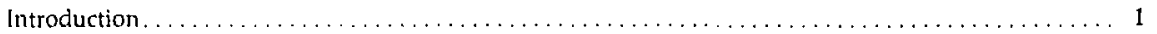

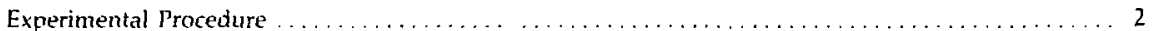

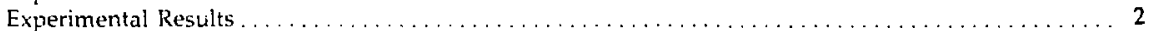

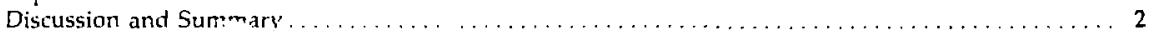

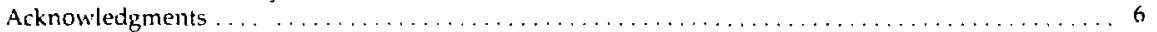

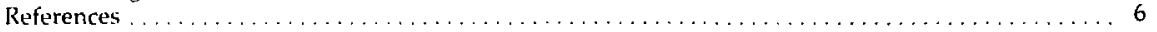




\section{List of Figures}

1. The electromagnetic permittivity, $\epsilon=\left(\epsilon^{\prime}-\mathrm{j} \epsilon^{\prime \prime}\right) \epsilon_{0}$, of basalt as a function of frequency for various volume fractions of water content $\ldots \ldots \ldots \ldots \ldots \ldots \ldots \ldots \ldots \ldots$

2. The real part of relative permittivity for vasalt as a function of volume fraction water content for various frequencies $\ldots \ldots \ldots \ldots \ldots \ldots \ldots \ldots \ldots \ldots \ldots$

3. Attenuation rate (inverse skin depth) for basalt as a function of volume fraction wate, content for various frequencies 


\title{
Basalt Nuclear-Waste Repository Remote Sensing Using Electromagnetic Techniques
}

\begin{abstract}
The electromagnetic permittivity and attenuation rate of basalt, from the Near Surface Test Facility of the Basalt Waste Isolation Project at Hanford, Washington, have been measured in the laboratory as a function of water content at frequencies from $25 \mathrm{MHz}$ to $1000 \mathrm{MHz}$. Both the permittivity and the attenuation rate are strongly related to water content of basalt in this frequency range. Completely dehydrated, the rock has a frequency-independent relative permittivity of about 8 and attenuation rates (inverse skin depths) of $0.04 \mathrm{~m}^{1}$ and $3.2 \mathrm{~m}^{-1}$ at $25 \mathrm{MHz}$ and $1000 \mathrm{MHz}$, respectively. When completely saturated by tap water to $6 \%$ by volume, the relative permittivity ranges from 16.5 to 10.0 and the attenuation ranges from $0.3 \mathrm{~m}^{-1}$ to $5.5 \mathrm{~m}^{-1}$ between $25 \mathrm{MHz}$ and $1000 \mathrm{MHz}$. The data indicate that high-frequency electromagnetic remote sensing techniques, such as those used in radar, cross-borehole tomography, and borehole logging, may be useful in characterizing proposed basalt repositories and monitoring established waste repositories. Electromagnetic methods are particularly suited to delineating water content of the rock and, when completely saturated, crack and pore porosity of the rock mass within a repository:
\end{abstract}

\section{Introdurtion}

Several techniques have been developed recintly for geophysical remote sensing using highfrequency eleciromagnetic waves. Surface and borchole radar sistems have been used to locate anomalie's (a.g. Suhler at al., 1970); cross-horehole radio-frequency tomography has been used for high-renolution mapping between pairs of boreholden (1.,g.. Dines and I.yile, 1979). Interest in diclectric well logging for vilfield characterization has increased with the successful development of high-frequency well logging took (Calvert, 1974; Rau. 1976). All of these techniques rely on propagation of relatively high-frequency (above a few megaherty) electromagnetic waves through the ground-a process only partially understood at present. As a result interpretation of data from these techniques is usually qualitative. The exception is electromagnetic well logging, which now allow's quantitative evaluation of oilfield formation parameters (Poley of al., 1978).

Water is the principal constituent controlling the electromagnetic characteristics of most geologic formations. Therefore, the objective of our
Jahoratory experiments was to determine the quantitative relation between measurable highfrequency electromagnetic paramelers and the water content of basalt. From thesc dita, we evalwated the value of geotomography and other electromagnetic techniques to quantitative characterization of the hydrology of a auclear-waste repository in basalt.

The sample used in our study is from the Near Surface Test Facility of the Basalt Waste lsolation Project at Hanford, Washingion. Although the data presented in this parer are for this specific basalt, they are useful for interpretation of data for different basalt types from a variety of geologic settings. These implications are discussed later.

The Experimental Procedure section describes the procedure used to prepare the rock samples and measure their high-frequency properties. The results of these experiments are presented under Experimental Results and evaluated in the Discussion and Summary. 


\section{Experimental Procedure}

The basalt core was provided by Rockwell International from the Near Surface Test Facility, Hole 5501-55014, at a depth of 3.29 inches from the rock fice. From this core, a crlinder was machined $5.025 \mathrm{~cm}$ long by $1.430 \mathrm{~cm}$ in diameter, with a hole $0.620 \mathrm{~cm}$ in diameter along the cylinder axis. The crlinder axis was oriented horizontally in the formation so the clectric field was radial to it. No cracks were visible in the machined sample.

The sample was dehydrated in a vacuum at $90 . \mathrm{C}$ for $14 t$ hours, during which its weight reached a minimum, indicating the loss of all moisture. The sample was then electromagnetially characterized to obtain its properties when completely dehydrated.

To achieve saturation, the sample was placed in tap water uncter 100 psi for 12 days, until its weight reached a maximum. The sample was again electromagnetically characterized; its porosity was calculated from the dry and saturated weights to be $5.95 \%$ of the total volume. After being air-dried for a short time, the sample was placed in a hermetically sealed container for 7 days to allow it to equilibrate with humidity in the container and produce honogeneity of the sample moisture content. Air-drying and equilibrating were repeated several times at different water contents to ensure a homogeneous water distribution in the sample before each measurement sequence. The sample was also characterized when saturated with a saturated solution of potassium chloride.

\section{Experimental Results}

The basalt sample was electromagnetically sharacterized between $25 \mathrm{MH} \%$ and $1013 \mathrm{MHz}$ at $52-\mathrm{MH} z$ intervals. The complex magnetic permeability: $\mu=\left(\mu^{\prime}-\mathrm{j}^{\prime \prime}\right) \mu_{1}$, and the electrical permittivity.e : ( $i^{\prime}$ je")e were calculated from the measured cattering parameters of the sample. The prermeability and permittivity of free space are $\mu_{11}$ and $e_{1}$. respectively: $i-1$ - 1 .

When $\mu$ (1.0 . . 0.0j), the parameters more casily delemined from field-measured quantities are propagation velocily, which is approximately we. and attenuation rate (inverse skin depth), which is

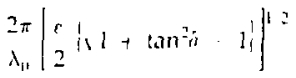

where,

$$
\begin{aligned}
c & =\text { speed of light in vacuum } \\
\lambda_{0} & =\text { free space wavelength }
\end{aligned}
$$$$
\tan \dot{o}=\mathrm{e}^{\prime \prime} / \mathrm{c}^{\prime} \text {. }
$$

Figure 1 shows the relative permittivity spectra of the basait. For all measurements, the magnetic permeability of bnsalt, within measurement accuracy, was that of a nonpermeable material: $\mu^{\prime}=1, \mu^{\prime \prime}=0$.

To emphrsize the relationships between the electromagnetic properties of basalt and its water content, Figs. 2 and 3 show the real relative permittivity and attemuation factor as functions of volume water content.

\section{Discussion and Summary}

The mont obvious and expected conclusion from the renults shown in Figs. I-3 is that both f. rmittivity and attenuation rate are strongly and $\because$-it matically rela ed to the water content of baalt. The datid ind,cate a monotonic increase in permotury and an approximately linear increase in attenuation rate with water content at all meaured trequancies. Measurements of hoth propagation velocity and signal amplitude in hasalt hould be encitsve to the moisture content of the rock mass. Therefore, below the water table, where the rock is completely saturated, measurement of signal amplitude and velocity would be a direct indication of porosity in the rock.

Because of this, data from cross-borehole tomography could be particularly useful since the measured distribution of electromagnetic attenuation between two boreholes could be interpreted as spatial variations in rock porosity. For example, at $25 \mathrm{MH} \boldsymbol{c}$ the measured attenuation rate would he $\sim 0.1 \mathrm{~m}^{-1}$ for a saturated region with porosity of $2-1 / 2 \%$; it would be $\sim 0.3 \mathrm{~m}^{-1}$ for a saturated 

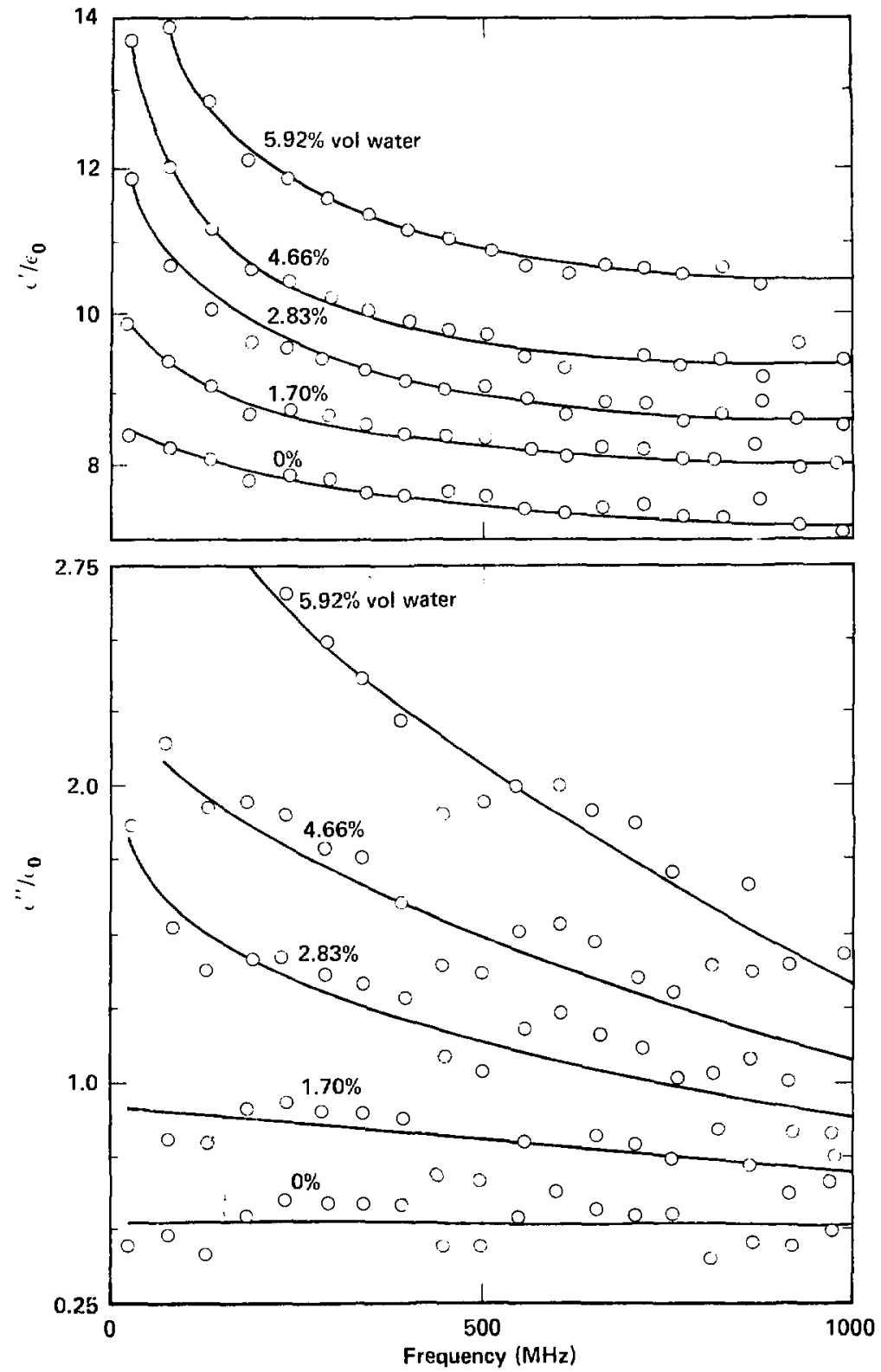

Figure 1. Tre electromagnetic permittivity, $\epsilon=\left(\epsilon^{\prime}-\mathbf{j} \epsilon^{\prime \prime}\right) \epsilon_{0}$, of basalt as a function of frequency for various volume frastions of water content. 


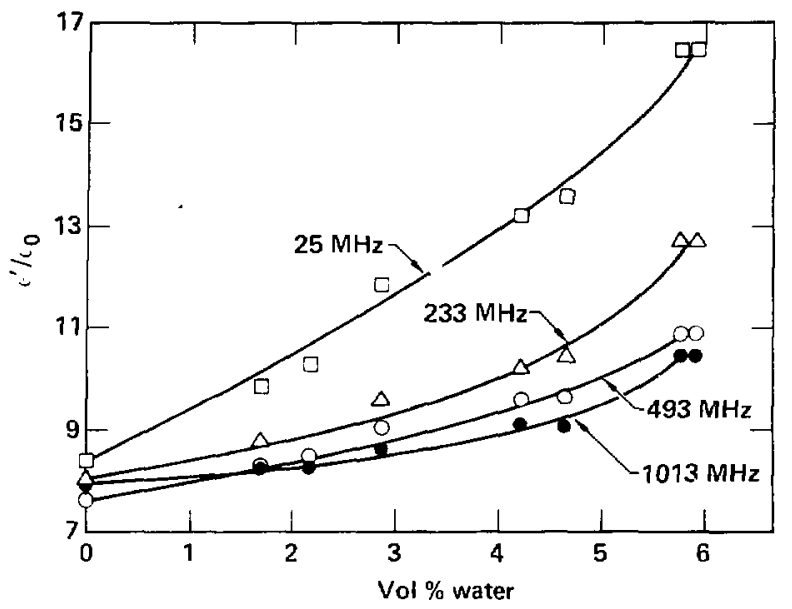

Figure 2. The real part of relative permittivity for basalt as a function of volume fraction water content for various frequencies.

region of h"t porosity. as might be expected in roik fractured by the large thermal load near a high-temperature-viaste canister.

Such attentation comtrasts are not difficult to renole' using geotomography (Okada at al., 1980). Ihe data also shew that, at frequencies typical of wom horehole tomegraphy (hetween $25 \mathrm{MHz}$ and lom N(HA). dry basalt has exceptionally small allentation rates $(0.04 \mathrm{~m}$ : or $25 \mathrm{~m}$ skin depth, at $25 \mathrm{NH} / \mathrm{/})$. which fermit iong transmission paths and harge borehole separations.

The dispersice character of basalt is strongly dependent on its water content. ligure l show's that with no noisture, basalt is approximately nendinpersise ower a wide frequency range. Both permillisily and sttentation are independent of irequency, making it an attractive medium for probing by radar. Tha pressure of moisture makes 1he babalt dispersive, diaperaion being proportumal to moisture content. This fact could be useful ton differentiating between inhomogeneities in a hasilt mon caused by pore or crack water and thume bused by another factor, such as variation 13 moneral sompostion.

f lectromagnetic probing relying on measurement of signal velocity is used for both crossbi reholdu imaging and radar. Pıopagation velocity in opproximalely proportional to (c') 1/2, and accufulte timing require's fast rise-lime, high frequency- sensitive to variations in moisture content (Fig. 2). It appears, thesefore, that these time-of-flight techniques will be relatively insensitive to moisture content variations in a basalt rock mass. This will be advantageous for radar and cross-borehole applications used to locate or map a.iomalies not relited to moisture variations. However, for applications to monitor changes in ur map spatial variations of water content, time-of-flight techniques will be relatively ineffective. This conclusion would probably also include mapping of fractured zones where the principal interaction mechanism results from enhanced water content in the fractured rock.

By contrast, attenuation rate is more sensitive to moisture changes, especially at the higher frequencies (Fig. 3). Received signal strength is proportional to e 2ur, which means that measured amplitudie is a strong function of attenuation rate. Because $: z$ is more sensitive at higher frequencies to variations in moisture, any electromagnetic attenuation meosurements of moisture content should use the highest practicahle frequency.

The sometimes irregular spectra of Fig. 1 ahove $800 \mathrm{MHz}$ are artifacts of data reduction. This noise is present because, at approximately $900 \mathrm{MHz}$, the length of the soturated sample is one-half wavelength; in this spectral region, the algorithm used to convert the measured scattering 


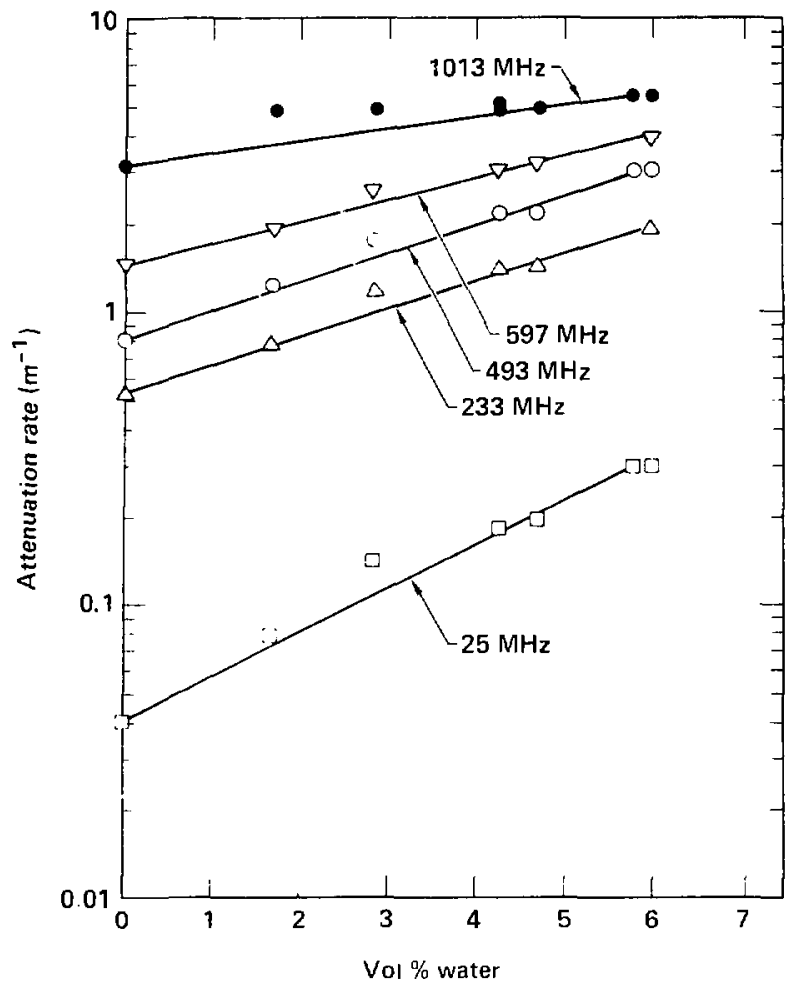

Figure 3. Attenuation rate (inverse skin depth) for basalt as a function of volume fraction water content for various frequencies.

content pulses. At higher frequencies, $t^{\prime}$ is less parameters to electrical permittivity is most susceptible to experimental errors. The other prominent spectral feature seen in Fig. 1, at about $4.50 \mathrm{MHz}$, is also caused by data error resulting from inexact calibration standards.

The data presented here quantitatively relate water content of hasalt to measurable electromagnetic paramiters. Undoubtedly the details of the relationship, will vary, even for different rocks of the same type but with different histories. When the relation is quantified for a given rock mass, however, high-frequency electromagnetic probing may be a useful tool in remotely characterizing the rock.
Especially below the water table where the rock is saturated, electromagnetic tomography and borehole logging could be used to map porosity distribution. Both spatial and temporal measurements of porosity in a rock mass could be useful. For example, stress call result in opening or closing of microcracks or pores; delineating these high-stress regions may help identify potential repository containment-failure modes.

In addition, long term monitoring of stress changes during part of a repository lifetime could be accomplished using high frequency electromagnetic techniques. Especially where porosity is dominantly from fractures and joints, electromagnetic techniques could provide a high-resolution 
map of these zones of high permeability. In fact, Rami*"' of al. (1982) have already demonstrated that fracture zones in granite can be mapped with high resolution using geotomography. Certainly, it is also simple to map fractured regions in basalt; using the laboratory data in this paper, it may be practical to make quantitative measurements of water content in the rock mass.

\section{Acknowledgments}

The authors would like to thank $\mathrm{D}$.. K. Thirumalai for making available a basalt core sample from the Near Surface Test Facility at the Rockwell-Hanford Operations, as well as K. Kishiyawa and J. Beatty for computer programming assistance. This work was funded by Rockwell International. Hanford Operatirns. and by the U.S. Department of Energy, Office of Basic Energy Science, G. Kolstad, Monitor.

\section{References}

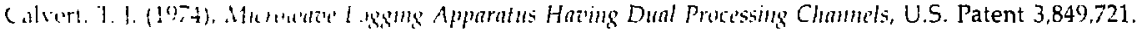
Dines, K. A. and R. I. I.tte (1979). "Computerized Geophysical Tomography," Proc. IEEE 67, 1065-1073. (Thada, I. T., E. F. Ldine, R. J. Lytle, and W. D. Daily (1980), Geofomography Applied at the Stripa Mine in Sittill. I wrence livernure National Laboratory, Livermore, Calif, UCRL-52961.

Toley 1. Ph.. I. I. Vootehoom, and [. J. de Wall (1978), "Use of VHF Dielectric Logging Measurements for Berehole formation Analysis," Lay Anahys 19(3), 8-30.

Rumurer. A. I.. F. I. Deadrick, and R. I. Lytle (1982), Cross-Borehole Fracture Mapping Using Electromagnetic

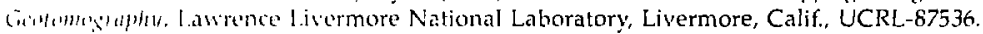

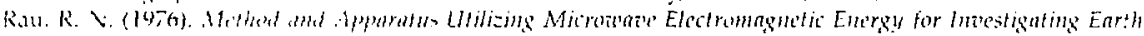
I.mmithm, L.S. Fotent $3,944.910$.

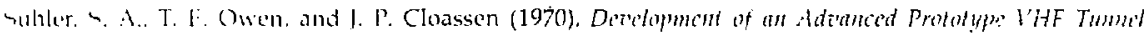
MPre LSAMIRDC. F. Belvoir, Va., Final Technical Report, Contract No. DAAKn2-70-C-0101

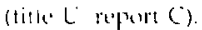

